\section{FRI0215 SIROLIMUS IN PATIENTS WITH SYSTEMIC LUPUS ERYTHEMATOSUS RELATED THROMBOCYTOPENIA (SLE-TP): A SINGLE-ARM, OPEN-LABEL CLINICAL TRIAL}

Chanyuan Wu, Qian Wang, LI Mengtao, Xiaofeng Zeng. Peking Union Medical College Hospital, Beijing, China

Background: Autoimmune thrombocytopenia (AITP) is common in systemic lupus erythematosus (SLE) patients and may be refractory to conventional therapies. SLE related thrombocytopenia (SLE-TP) patients have $\mathrm{T}$-cell dysfunction that was reported to be associated with the activation of the mammalian target of rapamycin (mTOR). Rapamycin (RAPA) inhibits antigen-induced T-cell proliferation and has been developed as a medication named sirolimus.

Objectives: We assessed safety, tolerance, and efficacy of sirolimus in a prospective, open-label clinical trial.

Methods: We did a single-arm, open-label study of sirolimus in patients with refractory SLE-TP unresponsive to, or intolerant of, conventional medications at Peking Union Medical College Hospital (PUMCH, Beijing, China). We enrolled refractory TP patients (aged $\geq 18$ years) with systemic lupus erythematosus (SLE) who visited our referral center since September 2017. We excluded patients with allergy or intolerance to sirolimus, patients with life-threatening manifestations of lupus, such as RPGN, NPLE or PAH and patients with uncured infection. All eligible participants had signed informed consents. Patients received oral sirolimus at a starting dose of $2 \mathrm{mg}$ per day for 3 days and a sequential dose of $1 \mathrm{mg}$ per day, with dose adjusted according to tolerance and to maintain a therapeutic range of $6-15 \mathrm{ng} / \mathrm{mL}$. Patients were treated with sirolimus for 6 months. Safety outcomes included tolerance as assessed by the occurrence of common side-effects. The primary efficacy endpoint was complete remission rate and partial remission rate at the sixth month. The secondary efficacy endpoint was thea remission rates at the third month. The efficacy endpoints were assessed in all patients who completed 3 or more months of treatment, and all patients who received at least one dose of treatment were included in the safety analyses.

Results: Between September 2017 and November 2018, 12 lupus patients (1 male and 11 female) were enrolled with an average age of 33.3y, average disease duration of 8.4 years. All patients haven't achieved remission with front-line therapy, including corticosteroids, intravenous immunoglobulin, and immunomodulatory agents, such as azathioprine, FK506, mycophenolate mofetil, and cyclosporine. After sirolimus therapy (2 weeks to 6 months), 5 of 12 patients achieved CRR. 11 patients have finished 4 months' assessment, and 9 of them achieved remission. One patient had mild oral ulcers and no other complications were noted. The study is still in regular follow-up. There will be more results and conclusions in the later period.

Table 1. Demographics and Characteristics for Patients With SLE-TP

\begin{tabular}{|c|c|c|c|c|c|c|}
\hline $\begin{array}{l}\text { Patient } \\
\text { No. }\end{array}$ & $\begin{array}{c}\text { Age } \\
(y)\end{array}$ & Gender & Prior Therapies & $\begin{array}{c}\text { Time to } \\
\text { Sirolimus } \\
\text { (y) }\end{array}$ & $\begin{array}{c}\text { Duration of } \\
\text { Sirolimus (m) }\end{array}$ & $\begin{array}{l}\text { Therapy } \\
\text { Outcome }\end{array}$ \\
\hline 1 & 36 & $\mathrm{~F}$ & GCs, MMF, AZA & 15 & 12 & $\mathrm{CR}$ \\
\hline 2 & 44 & $\mathrm{~F}$ & GCs, FK506 & 13 & 11 & $\mathrm{CR}$ \\
\hline 3 & 48 & $\mathrm{~F}$ & GCs, MMF & 7 & 11 & CR \\
\hline 4 & 35 & $\mathrm{~F}$ & GCS, MMF & 2 & 9 & $\mathrm{CR}$ \\
\hline 5 & 31 & $\mathrm{~F}$ & GCs, FK506 & 7 & 9 & $\mathrm{CR}$ \\
\hline 6 & 39 & $\mathrm{~F}$ & GCs, CTX & 8 & 6 & NR \\
\hline 7 & 30 & $\mathrm{~F}$ & $\begin{array}{c}\text { GCs, MMF, CsA, } \\
\mathrm{CH}\end{array}$ & 15 & 5 & PR \\
\hline 8 & 29 & $\mathrm{~F}$ & GCs, FK506 & 7 & 6 & NR \\
\hline 9 & 18 & M & $\begin{array}{c}\text { GCs, MMF, FK506, } \\
\text { CsA }\end{array}$ & 3 & 4 & PR \\
\hline 10 & 20 & $\mathrm{~F}$ & $\begin{array}{c}\text { GCs, CTX, FK506, } \\
\text { CsA, MMF, IVlg }\end{array}$ & 14 & 4 & PR \\
\hline 11 & 31 & $\mathrm{~F}$ & GCs, FK506 & 6 & 4 & PR \\
\hline 12 & 38 & $\mathrm{~F}$ & GCs, CsA & 4 & 2 & NR \\
\hline
\end{tabular}

AZA, azathioprine; $\mathrm{CH}$, Chinese herbs; $\mathrm{CR}$, complete response; CsA, cyclosporine; CTX, cyclophosphamide; FK506, tacrolimus; GCs, glucocorticoid; IVIG, intravenous

immunoglobulin; MMF, mycophenolate mofetil; NR, no response; PR, partial response.

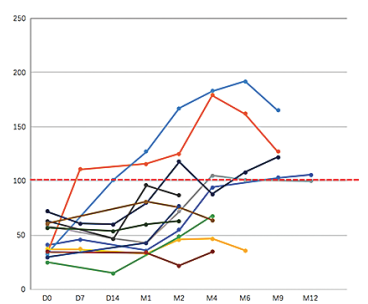

Conclusion: Sirolimus is effective for the treatment of refractory SLE-TP and can be a choice of the second-line treatment. Further prospective studies are needed to evaluate sirolimus as a therapeutic option for SLETP and to monitor for potential long-term side effects.

\section{REFERENCES:}

[1] Perl A. Nat Rev Rheumatol 2016; 12: 169-82.

[2] Morel L. Nat Rev Rheumatol 2017; 13: 280-90.

[3] Oaks Z, et al. Arthritis Rheumatol 2016; 68: 2728-39.

[4] Oaks Z, et al. Curr Rheum Rep 2016; 18: 73.

[5] Zhi-Wei Lai, et al. Lancet 2018 Mar 24;391(10126):1186-1196.

[6] Desmond Y.H. Yap, et al. J Rheumatol. 2018 Dec;45(12):1663-1670.

Acknowledgement: None

Disclosure of Interests: None declared

DOI: 10.1136/annrheumdis-2019-eular.7068

\section{FRI0216 IGURATIMOD MIGHT BE AN ALTERNATIVE OPTION FOR REFRACTORY LUPUS NEPHRITIS: A PRELIMINARY OBSERVATIONAL STUDY}

Qingran Yan, Yuening Kang, Ran Wang, Chunde Bao. Department of Rheumatology, Renji Hospital, School of Medicine, Shanghai Jiao Tong University, Department of Rheumatology, Renji Hospital, School of Medicine, Shanghai Jiao Tong University, Shanghai, China

Background: Despite significant advances in the management of patients with lupus nephritis (LN), a significant proportion of patients either do not respond to first-line immunosuppressive drugs, or relapse after initial remission. Iguratimod is a novel disease modifying anti-rheumatic drug that has been approved for treating rheumatoid arthritis in East Asia and has shown benefits in lupus animal model in our previous research.(1) Objectives: The aim of the present study was to make a preliminary observation on the efficacy and safety of iguratimod in treating refractory LN patients.

Methods: We have enrolled adult refractory LN patients who were eligible if they experienced at least two times of failure or relapse before enrollment. Failure was defined as no response to one certain immunosuppressive drug for at least six months. After enrollment, we simply switched their previous immunosuppressant to daily iguratimod $(25 \mathrm{mg}$ twice per day), while keeping all other medications. Complete/partial remission (PR/ CR) was used as the primary outcome. 24h urine protein, blood cell counts, liver and kidney function were routinely monitored.

Results: A total of 20 refractory LN patients had been enrolled (18 female and 2 male patients) since 2015. At enrollment, the median proteinuria was $2.588 \mathrm{~g} / 24 \mathrm{~h}$ (range: $0.98-13.79 \mathrm{~g} / 24 \mathrm{~h}$ ). None of them had overt extra-renal involvement. All of them had biopsy-proven LN (class III/IV/V) and two patients agreed repeated biopsy before switching to iguratimod. The median prednisone dosage was $10 \mathrm{mg} / \mathrm{d}$ (range: $5-35 \mathrm{mg} / \mathrm{d}$ ). One patient was lost to follow-up and one withdrew from the study. Of the remaining 18 patients, 16 patients achieved PR/CR and 2 did not respond to iguratimod. Of the 16 patients who achieved remission, 3 had renal relapse after initial $P R$ and 1 had extra-renal flare after initial $C R$. One PR patient withdrew from the study due to severe anemia and another due to incompliance. For the remaining 10 patients who were still in follow-up, the median follow-up was 84 weeks (range: 28-144 